\title{
Comparative Analysis by Polymerase Chain Reaction Amplified Minicircles of Kinetoplast DNA of a Stable Strain of Trypanosoma cruzi from São Felipe, Bahia, its Clones and Subclones: Possibility of Predominance of a Principal Clone in this Area
}

\author{
Rozalia F Campos*, Marilda S Gonçalves, Eliana AG dos Reis, Mitermayer \\ G dos Reis, Sonia G Andrade ${ }^{+}$
}

\begin{abstract}
Laboratório de Doença de Chagas Experimental e Laboratório de Patologia e Biologia Molecular, Centro de Pesquisas Gonçalo Moniz-Fiocruz, Rua Valdemar Falcão 121, 40295-001 Salvador, BA, Brasil *Departamento de Ciências Biológicas, Universidade Estadual de Feira de Santana, Feira de Santana, BA, Brasil
\end{abstract}

Molecular characterization of one stable strain of Trypanosoma cruzi, the 21 SF, representative of the pattern of strains isolated from the endemic area of São Felipe, State of Bahia, Brazil, maintained for 15 years in laboratory by serial passages in mice and classified as biodeme Type II and zymodeme 2 has been investigated. The kinetoplast DNA ( $k D N A)$ of parental strain, 5 clones and 14 subclones were analyzed. Schizodeme was established by comparative study of the fragments obtained from digestion of the 330-bp fragments amplified by polymerase chain reaction (PCR) from the variable regions of the minicicles, and digested by restriction endonucleases Rsa I and Hinf I. Our results show a high percentual of similarity between the restriction fragment lenght polymorphism (RFLP) for the parental strain and its clones and among these individual clones and their subclones at a level of 80 to 100\%.This homology indicates a predominance of the same "principal clone" in the 21SF strain and confirms the homogeneity previously observed at biological and isozymic analysis. These results suggest the possibility that the T. cruzi strains with similar biological and isoenzymic patterns, circulating in this endemic area, are representative of one dominant clone.

The presence of "principal clones" could be responsible for a predominant tropism of the parasites for specific organs and tissues and this could contribute to the pattern of clinico-pathological manifestations of Chagas's disease in one geographical area.

Key words: Trypanosoma cruzi - strains - clones - molecular characterization - schizodeme - Bahia - Brazil

Trypanosoma cruzi strains are represented by parasite populations with different biological, biochemical and genetic characteristics (Andrade 1974, Morel et al. 1980, Miles et al. 1981a). These parameters have been used for classification of $T$. cruzi strains into biological types or biodemes (Andrade 1974), different zymodemes (Miles et al. 1980) and schizodeme analysis of kinetoplast DNA (kDNA) minicircles with restriction endonucleases (Morel et al. 1980); this technique reveals polymorphic fragments of kDNA (RFLP). The possibility of a clonal structure for $T$. cruzi strains has been proposed by Tibayrenc et al. (1986)

This research was supported by International Centers for Infectious Disease Research, Grant 5UO1-AII630517, National Institutes of Health, USA.

${ }^{+}$Corresponding author. Fax: +55-71-356.4292. E-mail: pgpat@svn.com.br

Received 7 May 1998

Accepted 4 September 1998 and Tibayrenc and Ayala (1988), suggesting the existence of clonal lines without sexual interactions, separated by a long evolutionary process. The presence of principal clones may bear influence on the biological behaviour and pathogenicity of the strains. Clonal homogeneity (Dvorak et al. 1980, Goldberg \& Silva Pereira 1983, Gomes et al. 1991) or heterogeneity (Engel et al. 1982, Marques de Araujo \& Chiari 1988, Lima et al. 1990) has been detected by the study of clones from different $T$. cruzi strains. Considering the stability of the biological characters of some laboratory strains, it seems interesting to investigate the genetic patterns of their clonal populations. With this objective the $21 \mathrm{SF}$ strain, isolated from one patient of São Felipe, Bahia, an endemic area of Chagas' disease representing the prototype of 17 isolates from this area, maintained in laboratory for 15 years with stable biological and biochemical characteristics, has been cloned. The clones have maintained the same patterns already described for the parental strain (Campos \& Andrade 
1996). In the present study it was investigated if a correspondent uniformity of the clones and subclones could be demonstrated at a genetic level through the analysis of the kDNA. For molecular characterization, the schizodeme pattern of the clonal population was studied by polymerase chain reaction (PCR) of the variable region of the $\mathrm{kDNA}$ minicircle according to Avila et al. (1990) and by analysis of restriction endonuclease digested fragments. The degree of similarity between the parental strain, the isolated clones and subclones suggests predominace of a "principal clone" in the 21 SF strain, responsible for the pattern of behavior of this strain and its pathogenicity.

\section{MATERIALS AND METHODS}

T. cruzi strain - The $21 \mathrm{SF}$ strain has been isolated by xenodiagnosis from a patient with the acute form of the Chagas' disease, from São Felipe, Bahia. It was characterized as biodeme Type II (Rocha Filho 1979) and zymodeme 2 (Miles et al. 1980). Since then, it has been maintained in the laboratory by successive passages into mice and by cryopreservation in liquid nitrogen.

Cloning and subcloning - As previously described (Campos \& Andrade 1996), blood from mice infected with the $21 \mathrm{SF}$ strain was centrifuged at $900 \mathrm{~g}$, the supernatant diluted in PBS and distributed in multi-well microtiter culture plates and examined in an inverted microscope. Wells containing only one trypomastigote were filled with $\mathrm{pH}$ 7.2PBS, and the suspension collected by syringe and injected into one newborn mouse. Trypanosomes isolated from infected mice were defined as clones (Dvorak 1985). The first passage was performed by collecting blood from the infected newborn mice and inoculating it into suckling mice.

Five initial clones were isolated and identified as $\mathrm{C} 1, \mathrm{C} 2, \mathrm{C} 3, \mathrm{C} 4, \mathrm{C} 5$. By subcloning procedures, 14 subclones were obtained: 3 from $\mathrm{C} 1,2$ from $\mathrm{C} 2,3$ from $\mathrm{C} 3,3$ from $\mathrm{C} 4$ and 3 from $\mathrm{C} 5$. Subclones were identified by the name of the parental clone plus the subclone name R1, R2, R3, etc. (for example, C1R1, C2R2).

Clones and subclones were characterized according to biological and biochemical behavior and the data on the experimental groups has been published elsewhere (Campos \& Andrade 1996). Briefly, groups of 20 mice weighing 10 to $12 \mathrm{~g}$ were infected with trypomastigotes from each clone and subclone, in the 4th passage in mice. Biological behavior has been evaluated by several parameters as described by Andrade (1974), including parasitemic evolution, morphology in the peripheral blood and virulence. Isozymic characters were determined according to Miles et al. (1980).

Genetic characterization - Hemoculture in axenic Warren medium was inoculated with the blood of infected mice at the 5th passage, and incubated at $28^{\circ} \mathrm{C}$. After washing in $\mathrm{pH}$ 7.2-PBS, the culture forms ressuspended to a concentration of $1 \times 10^{9}$ parasites were cryopreserved in liquid nitrogen.

kDNA analysis - kDNA was extracted from the $21 \mathrm{SF}$ strain, its clones and subclones according to Gonçalves et al. (1984). Sample integrity was confirmed after being loaded in a $2 \%$ agarose gel electrophoresis in TAE buffer (0.04 M Tris-acetate, $0.001 \mathrm{M}$ EDTA) and UV light examined after ethidium bromide staining. PCR was performed in $100 \mathrm{ml}$ reaction mixtures containing $10 \mathrm{mM}$ Tris$\mathrm{HCl}$ (pH 8.4), $50 \mathrm{mM} \mathrm{KCl}, 2.0 \mathrm{mM} \mathrm{MgCl} 2,200$ $\mathrm{mM}$ of each dNTP, $2 \mathrm{ml}$ DNA (@ $0.5 \mathrm{mg}$ ), $2.5 \mathrm{U}$ of Taq polymerase (Perkin Elmer-Cetus Corporation), 2 pmols of previously described oligonucleotide primers (Avila et al. 1990) (Table I). After an initial 5 min denaturation step at $94^{\circ} \mathrm{C}, 35$ cycles of amplification were performed on DNA Thermal Cycler (Perkin Elmer-Cetus gene Amp PCR System 9600) with a step program consisting of $45 \mathrm{sec}$ denaturation at $94^{\circ} \mathrm{C}, 45 \mathrm{sec}$ annealing at $55^{\circ} \mathrm{C}$ and $1 \mathrm{~min}$ extension at $72^{\circ} \mathrm{C}$. Additional 10 min extension step at $72^{\circ} \mathrm{C}$ was performed at the end of reaction. Each PCR round had a negative control and a DNA Leishmania control that were used to test the purity and specificity of the reagents and primers, respectivelly. In order to confirm the results, PCR products of the predicted size (330 bp) were separated by electrophoresis in a $2 \%$ agarose gel, transferred to nylon membrane (Hybond $\mathrm{N}+$, Amersham) by Southern-blot technique (Southern 1975), hybridized with one oligonucleotide probe from different sequence of the minicircle region (Avila et al. 1990) (Table I). The oligonucleotide probe was 3'-end-labelled with fluorescein -11- d UTP (Fl - d UTP) catalyzed by terminal deoxynucleotidyl transferase (tdt), by the enhanced chemiluminescence associated with horseradish peroxidase catalyzed oxidation of luminol, (ECL 3'oligolabelling and Detection Systems, Amersham). Autoradiography was performed using Hyperfilm b Max (Amersham) after $5 \mathrm{~min}$ at room temperature exposition.

Dot-blot (Mainfold-BRL) hybridization was also performed, after PCR product denaturation in $0.4 \mathrm{M} \mathrm{NaOH}, 2.5 \mathrm{mM}$ EDTA solution and nylon membrane transference (Hybond $\mathrm{N}+$, Amersham) (10 mg of amplified DNA for each sample). The oligonucleotide probe labelling and the hybridization were performed using the same 3'-end-labelled system above described (Amersham).

The kDNA analysis was performed by comparative study of the fragments obtained from the digestion of amplified minicircle DNA variable region by Rsa I and Hinf I restriction endonu- 
cleases, according to the manufacturer's procedures (Gibco-BRL). The DNA fragments were separated by electrophoresis in a $12.5 \%$ polyacrylamide gel (Phast-System, Pharmacia Biotech), and silver stained (Pharmacia Biotech).

Statistical analysis - The determination of the percentual of similarity was performed by comparing the RFLP of variable region of minicircles of the kDNA in the schizodeme of the parental strain, its clones and subclones, as described by Solari et al. (1992). For that it has been utilized the formule: $2 \mathrm{Nxy} x \mathrm{100/Nx}+\mathrm{Ny}$, where Nxy represents the total number of common bands, $\mathrm{Nx}$ and $\mathrm{Ny}$ represent the total number of bands in the stocks $\mathrm{x}$ and $\mathrm{y}$.

\section{RESULTS}

Data concerning the results of biological and isoenzymic characterization of the several clones and subclones has been described in a previous paper (Campos \& Andrade 1996). In summary the biological characterization has confirmed all the clones and subclones as biodeme Type II, similar to the parental strain, although with a slight variation in the parasitemic pattern of the clone C5 that determined the lowest levels and the latest peak of parasitemia (Fig. 1).

In respect to the isozymic patterns, all five clones and the subclones have been included into zymodeme 2, as well the $21 \mathrm{SF}$ strain (Campos \& Andrade 1996).

Genetic characterization by a comparative analysis of the kDNA minicircles variable region, after Rsa I and Hinf I digestion, disclosed the results that are summarized at Table II). (i) The

\section{TABLE I}

Oligonucleotide primers and probe sequences used to perform polymerase chain reaction and hybridization of the conserved region of the minirepeats of Trypanosoma cruzi kDNA minicircles

\begin{tabular}{ll}
\hline Oligonucleotides & Sequences 5' ${ }^{\circledR} 3$ \\
\hline P 35 (primer sense) & AAATAATGTACGGG(T/G)GAGATGCATGA \\
P 36 (primer sense) & GGGTTCGATTGGGGTTGGTGT \\
P 67 (probe) & TGGTTTTGGGAGGGG(C/G) $(\mathrm{G} / \mathrm{C})(\mathrm{T} / \mathrm{G}) \mathrm{TCAA}(\mathrm{A} / \mathrm{C}) \mathrm{TTT}$ \\
\hline
\end{tabular}

P 35, P 36 and P 67: hibridize to the conserved region within the minirepeats of T. cruzi kDNA minicircles (Avila et al. 1990).

TABLE II

Percentuals of similarity resulting from the analysis of the restriction fragment lenght polymorphisms of the several schizodemes

\begin{tabular}{|c|c|c|c|c|c|c|c|c|c|c|c|c|}
\hline \multirow{2}{*}{$\begin{array}{l}\text { Strain and } \\
\text { clones } \\
\text { Clones and } \\
\text { subclones }\end{array}$} & \multicolumn{2}{|c|}{$21 \mathrm{SF}$} & \multicolumn{2}{|c|}{$\mathrm{C} 1$} & \multicolumn{2}{|c|}{$\mathrm{C} 2$} & \multicolumn{2}{|c|}{ C3 } & \multicolumn{2}{|c|}{$\mathrm{C} 4$} & \multicolumn{2}{|c|}{$\mathrm{C} 5$} \\
\hline & Rsa I & Hinf I & Rsa I & Hinf I & Rsa I & Hinf I & Rsa I & Hinf I & Rsa I & Hinf I & Rsa I & Hinf I \\
\hline $\mathrm{C} 1$ & 85 & 87 & & & & & & & & & & \\
\hline $\mathrm{C} 2$ & 93 & 83 & 96 & 61 & & & & & & & & \\
\hline C3 & 100 & 92 & 92 & 83 & 96 & 97 & & & & & & \\
\hline $\mathrm{C} 4$ & 82 & 100 & 94 & 82 & 83 & 88 & 92 & 89 & & & & \\
\hline C5 & 67 & 85 & 95 & 79 & 90 & 85 & 72 & 81 & 89 & 93 & & \\
\hline C1R1 & 82 & 100 & 90 & 96 & & & & & & & & \\
\hline C1R2 & 82 & 91 & 90 & 95 & & & & & & & & \\
\hline C1R3 & 82 & 100 & 82 & 96 & & & & & & & & \\
\hline C2R1 & 96 & 83 & & & 96 & 96 & & & & & & \\
\hline $\mathrm{C} 2 \mathrm{R} 2$ & 92 & 92 & & & 93 & 100 & & & & & & \\
\hline C3R1 & 97 & 82 & & & & & 97 & 96 & & & & \\
\hline C3R2 & 94 & 96 & & & & & 100 & 96 & & & & \\
\hline C3R3 & 97 & 93 & & & & & 97 & 79 & & & & \\
\hline C4R1 & 78 & 92 & & & & & & & 96 & 96 & & \\
\hline C4R2 & 87 & 96 & & & & & & & 96 & 96 & & \\
\hline C4R3 & 82 & 62 & & & & & & & 82 & 79 & & \\
\hline C5R1 & 61 & 79 & & & & & & & & & 95 & 92 \\
\hline C5R2 & 64 & 79 & & & & & & & & & 91 & 92 \\
\hline C5R3 & 64 & 85 & & & & & & & & & 91 & 92 \\
\hline
\end{tabular}

Analysis was performed among the parental strain, clones and subclones; between clones and between clones and subclones (according to Solari et al. 1992). 


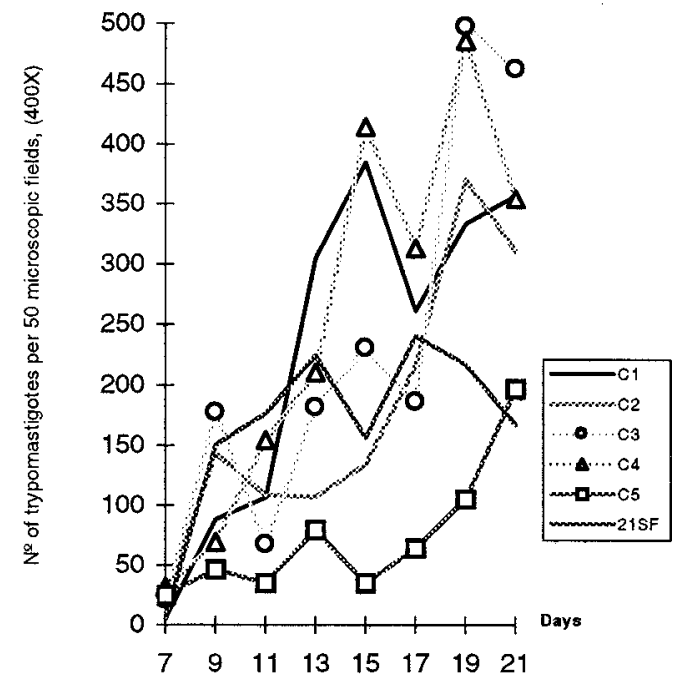

Fig. 1: parasitemia in mice infected with the $21 \mathrm{SF}$ strain and derived clones and subclones. The parasitemic peaks of the 21 $\mathrm{SF}$ strain and clones $\mathrm{C} 1, \mathrm{C} 2, \mathrm{C} 3, \mathrm{C} 4$ are irregular and ocurred between 12 and 20 days; the clone $\mathrm{C} 5$ showed a delayed peak at 21 days.

percentual of similarity between the parental strain and the clones $\mathrm{C} 1, \mathrm{C} 2, \mathrm{C} 3$ and $\mathrm{C} 4$ varied from 82 to $100 \%$ for the two enzymes, Rsa I and Hinf I, (Fig. 4). For the clone C5 the percentual of similarity with the parental strain was of $67 \%$ for the enzyme Rsa I and $85 \%$ for the Hinf I; (ii) comparison between the parental strain and subclones have shown similarity from 78 to $100 \%$; C5R1, C5R2, C5R3 subclones showed similarity levels varying from 61 to $64 \%$; (iii) comparison between the several clones have disclosed indices of homology for the enzyme Rsa I from 70 to $97 \%$; with the enzyme Hinf I the homology varied from 76 to 100\%; (iv) the homology between each clone and its subclone varied from 79 to $100 \%$ (Fig. 4). PCR amplification of the $330 \mathrm{bp}$ has been detected in parental strain, its clones and subclones (Fig. 2A). All samples disclosed positive hybridization with P67 (Fig. 2B).

\section{DISCUSSION}

T. cruzi strains are stable populations that putatively represent the equilibrium of multiple clones. The concept of strain according to Thompson and Lymbery (1990) could not be based only on the genetical differences between populations but also in differences in one or more characters of epidemiological importance. This view is important when we consider $T$. cruzi strains and the correlations of the genetical patterns with biological behavior. The "stability" of T. cruzi strains can be considered as the possibility of maintenance of its populations in an equilibrium after several
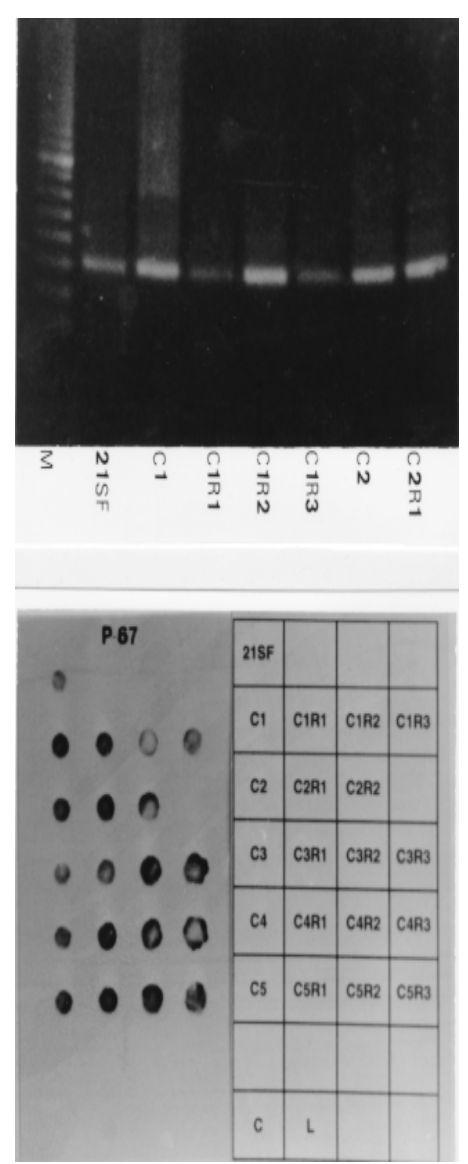

Fig. 2: A - Amplified products (polymerase chain reaction) of the $330 \mathrm{bp}$ DNA minicircles variable region from $21 \mathrm{SF}$ (parental strain) its clones ( $\mathrm{C} 1$ and $\mathrm{C} 2)$ and respective subclones (C1R1, C1R2, C1R3, C2R1). Line M: marker. This represents the pattern of amplification of the parental strain, all its clones and subclones. B - Positive hybridization by dot-blot technique present in all samples analyzed with the probe 67.

laboratory passages in different conditions or through different procedures such as axenic cultures, animal passages, cryopreservation or vector passages (Magalhães et al. 1985, Magalhães \& Andrade 1991). The clonal homogeneity could be considered as an important factor to this stability. Gomes et al. (1991) has observed the stability of isoenzyme and kDNA patterns in four strains of $T$. cruzi of different zymodemes, after successive cloning; they have shown that in three of them there were identical isoenzyme and kDNA patterns between themselves and their parental strains.

The predominance of a clone with well defined characteristics in the constitution of a stable strain, could be a key for the analysis of the parasite populations that predominate in one endemic area. The $21 \mathrm{SF}$ strain of $T$. cruzi, has been initially charac- 


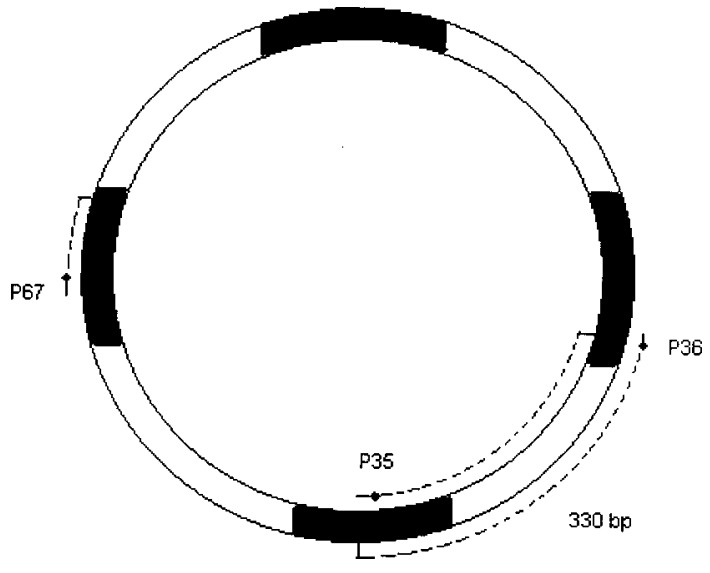

Fig. 3: a schematic representation of the organization of the minirepeat regions on an individual minicircle with the primer sets 35 and 36, probe 67, and their amplification products, indicated by dotted lines (Modified from Sturm et al. 1989).

terized as biodeme Type II (Andrade 1974) and zymodeme 2 (Miles et al. 1980, Andrade et al. 1983), similar to a significant number of strains from the same area of São Felipe. After a long period of maintenance in laboratory since its isolation, the behavioral stability of this strain was remarkable. After cloning and the finding of biological and biochemical similarity between the clones, subclones and the parental strain (Campos \& Andrade 1996), the molecular analysis was a further step to characterize them at a genetic level.

Schizodeme analysis of $T$. cruzi has been largely utilized to determine the molecular constitution of strains and to distinguish strains with close biological characteristics. In comparison to total kDNA analysis, digestion patterns that result from the amplification of the kDNA variable minicircle region appear to discriminate more accurately strains from the same geographical area which present the same biological and biochemical characteristics (Avila et al. 1990). Analysis of the variable region of the kDNA minicircle has been considered as a marker to determine species, to distinguish the apparently similar strains and to classify them as schyzodemes (Sturm et al. 1989, Avila et al. 1990).

In the present study, the specificity of the fragments of minicircles of kDNA for $T$. cruzi was confirmed using the probe 67 (Degrave et al. 1988, Sturn et al.1989). It became clear that, by using Solari's numerical taxonomy (Solari et al. 1992), the strain 21 SF discloses a high degree of similarity between the parental strain and its clones, as well as between the several clones or between the clones and subclones. To a lower percentual of simi-

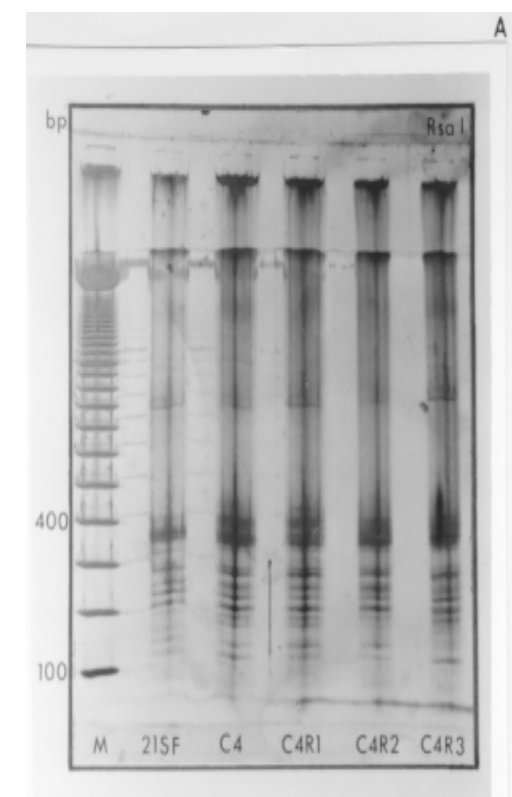

B

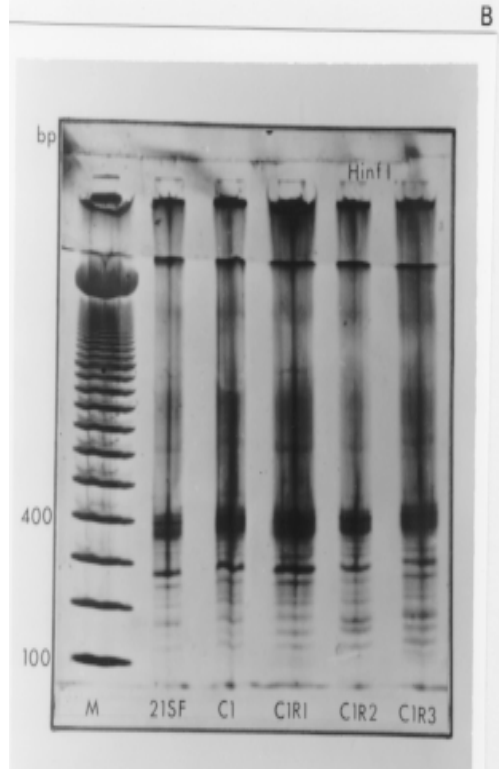

Fig. 4: analysis of the $21 \mathrm{SF}$ strain schizodeme amplification products by polymerase chain reaction. The 330 bp product was digested by Rsa I and Hinf I, separated through $12.5 \%$ polyacrylamide gel and silver stained. The $\mathrm{M}$ band represents the 100 bp ladder DNA marker. A: 21 SF - parental strain; C4 clone; C4R1, C4R2, C4R3 - subclones (Rsa I). B: 21 SF - parental strain; C1 - clone; C1R1, C1R2, C1R3 - subclones (Hinf I). In both $\mathrm{A}$ and $\mathrm{B}$ : a high degree of similarity between the RFLP patterns of the several schizodemes is shown.

larity, as observed with clone C5, also corresponds a slight difference in the parasitemic pattern of this same clone, with maintenance of other biological parameters and isoenzymic profiles (Campos \& Andrade 1996). This also suggests that those last 
characteristics are genetically determined.

Further studies, including the genetical sequences and the analysis of a higher number of clones, will be necessary to confirm the degree of homology found in this study. According to Tibayrenc and Ayala (1988), well-adapted clones can predominate and be selected by environmental conditions and circulate in different areas. This seems important when we consider the possibe influence of the parasite strain in the determination of the clinical presentations of Chagas' disease in different geographical areas, as previously suggested (Andrade 1974, Miles et al. 1981b). In the endemic area of São Felipe, as well as in other geographical areas, as Mambaí, GO, a predominance of strains with the same characteristics is well determined (Andrade \& Magalhães 1997). Considering the several aspects of the infection with $T$. cruzi, the presence of the same biological and biochemical pattern of strain in one endemic area could be important, not only considering the predominant type of clinical manifestations and organs envolvement, but also in relation to the response to chemotherapy, as has been demonstrated (Andrade et al. 1992) for strains isolated from the endemic area of Montalvania, MG, where an agreement of $82 \%$ was seen between the experimental and clinical results of treatment with benznidazole or nifurtimox. This means that the correlations of the strain type and chemotherapy, already demonstrated for the experimental animals also occurs in man.

The genetic evidence of a clonal homogeneity in the parasite strains represents a tool for the understanding of different aspects of the disease in different regions, and contribute to the molecular epidemiology of Chagas' disease.

The presence of a "principal clone" circulating in one endemic area can be responsible for the predominance of the same pattern of strains isolated from patients of areas as São Felipe, all of them included into biodeme Type II and zymodeme 2 . These "principal clones" could be responsible for a predominant tropism of the parasites for specific organs and tissues, and this, certainly will contribute to the pattern of clinicopathological manifestations in one geographical area.

\section{ACKNOWLEDGEMENTS}

To Dinalva França for preparing T. cruzi cultures.

\section{REFERENCES}

Andrade SG 1974 Caracterização de cepas do Trypanosoma cruzi isoladas no Recôncavo Baiano. Rev Patol Trop 3: 65-121.

Andrade SG, Magalhães JB 1997. Biodemes and zymodemes of Trypanosoma cruzi strains: correlations with clinical data and experimental pathology. Rev Soc Bras Med Trop 30: 27-35.

Andrade SG, Rassi A, Magalhães JB, Ferriolli Filho F, Luquetti AO 1992. Specific chemotherapy of Chagas disease: a comparison between the response in patients and experimental animals inoculated with the same strains. Trans $R$ Soc Trop Med Hyg 86: 624626.

Andrade V, Brodskyn C, Andrade SG 1983. Correlation between isoenzyme patterns and biological behaviour of different strains of Trypanosoma cruzi. Trans $R$ Soc Trop Med Hyg 76: 796-799.

Avila H, Gonçalves AM, Nehme NS, Morel CM, Simpson L 1990. Schizodeme analysis of Trypanosoma cruzi stocks from South and Central America by analysis of PCR - amplified minicircle variable region sequences. Mol Biochem Parasitol 42: 175188.

Campos RMF, Andrade SG 1996. Characterization of subpopulations (clones and subclones) of the 21SF strain of Trypanosoma cruzi after lasting maintenance in the laboratory. Mem Inst Oswaldo Cruz 91: 795-800.

Degrave W, Fragoso SP, Britto C, van Heuverswyn H, Kidane GZ, Cardoso MAB, Mueller RU, Simpson L, Morel CM 1988. Peculiar sequence organization of kinetoplast DNA minicircles from Trypanosoma cruzi. Mol Biochem Parasitol 27: 63-70.

Dvorak JA 1985. Single cell isolates of Trypanosoma cruzi: How and why? Rev Soc Bras Med Trop 18 Suppl: 29-38.

Dvorak J, Hartman DL, Miles MA 1980. Trypanosoma cruzi: correlation of growth kinetics to zymodeme type in clones derived from various sources. $J$ Protozool 27: 472-474.

Engel JC, Dvorak JA, Segura EL, Crane MJ 1982. Trypanosoma cruzi: Biological characterization of 19 clones derived from two chronic chagasic patients. I. Growth kinetics in liquid medium. J Protozool 29: 555-560.

Goldberg SS, Silva Pereira AA 1983. Enzyme variation among clones of Trypanosoma cruzi. J Protozool 69: 91-96.

Gomes ML, Romanha AJ, Gonçalves AM, Chiari E 1991. Stability of isoenzyme and kinetoplast DNA (k-DNA) patterns in successively cloned Trypanosoma cruzi populations. Mem Inst Oswaldo Cruz 86: 379-385.

Gonçalves AN, Nehme NS, Morel CM 1984. Trypanosomatid characterization by schizodeme analysis, p. 95-109. In CM Morel, Genes and Antigens of Parasites. A Laboratory Manual, 2 ed., Fiocruz, Rio de Janeiro.

Lima MT, Jansen AM, Rondinelli E, Gattass CR 1990. Trypanosoma cruzi: properties of a clone isolated from CL strain. Parasitol Res 77: 77-81.

Magalhães JB, Andrade SG 1991. Estudo do comportamento de cepas de Trypanosoma cruzi após passagem em diferentes espécies de triatomíneos. Rev Soc Bras Med Trop 24: 209-216.

Magalhães JB, Pontes AL, Andrade SG 1985. 
Comportamento das cepas Y e Peruana do Trypanosoma cruzi no camundongo, após passagem em diferentes meios. Mem Inst Oswaldo Cruz 80: 41-50.

Marques de Araújo S, Chiari E 1988. Caracterização biológica de clones das cepas Y, CL e MR de Trypanosoma cruzi em camundongos $\mathrm{C} 3 \mathrm{H}$ isogênicos. Mem Inst Oswaldo Cruz 83: 175-181.

Miles M, Lanham S, Souza A, Povoa M 1980. Further enzymic characters of Trypanosoma cruzi and their evaluation for strain identification. Trans $R$ Soc Trop Med Hyg 74: 221-237.

Miles MA, Povoa MM, Prata A, Cedillos RA, Souza AA, Macedo V 1981a. Do radically dissimilar Trypanosoma cruzi (zymodemes) cause Venezuelan and Brazilian forms of Chagas' disease? Lancet 20: 1338-1340.

Miles MA, Povoa MM, Souza AA, Lainson R, Shaw JJ, Ketteridge DS 1981b. Chagas' disease in the Amazon Basin: II. The distribution of Trypanosoma cruzi zymodemes 1 and 3 in Pará State, north Brazil. Trans $R$ Soc Trop Med Hyg 75: 667-674.

Morel C, Chiari E, Camargo E, Mattei D, Romanha A, Simpson L 1980. Strains and clones of Trypanosoma cruzi can be characterized by pattern of restriction endonuclease products of kinetoplast DNA minicircles. Proc Natl Acad Sci USA 77: 6810-6814.

Rocha Filho FD 1979. Estudo Comparativo de Cepas do T. cruzi de Diferentes Procedências (Aspéctos Antigênicos, Morfológicos e Histopatológicos), MSc Thesis, Universidade Federal da Bahia, Salvador, $85 \mathrm{pp}$.

Solari A, Muñoz S, Venegas J, Wallace A, Aguilera X, Apt W, Brenière SF, Tibayrenc M 1992. Characterization of Chilean, Bolivian, and Argentinian Trypanosoma cruzi populations by restriction endonuclease and isoenzyme analysis. Exp Parasitol 75: 187-195.

Southern EM 1975. Detection of specific sequences among DNA fragments separated by gel electrophoresis. J Mol Biol 98: 503-517.

Sturm NR, Degrave W, Morel C, Simpson L 1989. Sensitive detection and schizodeme classification of Trypanosoma cruzi cells by amplification of kinetoplast minicircle DNA sequences: use in diagnosis of Chagas disease. Mol Biochem Parasitol 33: 205-214 .

Tibayrenc M, Ayala F 1988. Isozyme variability in Trypanosoma cruzi, the agent of Chagas' disease: genetical, taxonomical and epidemiological significance. Evolution 42: 277-292.

Tibayrenc M, Ward P, Moya A, Ayala F 1986. Natural populations of Trypanosoma cruzi, the agent of Chagas disease, have a complex multiclonal structure. Proc Nat Acad Sci USA 83: 115-119.

Thompson RCA, Lymbery AJ 1990. Intraspecific variation in parasites - what is a strain? Parasitol Today 6: $345-348$ 
PCR Amplified Minicircles of kDNA of 21 SF T. cruzi • Rozália F Campos et al. 